\title{
Factors Affecting the Spatial Distribution of Visceral Leishmaniasis in an Urban Area of Recent Emergence in Inner Brazil

\author{
José Cláudio Simão ${ }^{1^{*}}$ (D), Cassiano Victória ${ }^{2}$ (D) and Carlos Magno Castelo Branco \\ Fortaleza ${ }^{1}$ iD
}

${ }^{1}$ Department of Tropical Diseases, Botucatu Medical School, São Paulo State University (UNESP), City of Botucatu, São Paulo State, Brazil

${ }^{2}$ Department of Veterinary Hygiene and Public Health, Faculty of Veterinary, São Paulo State University (UNESP), City of Botucatu, São Paulo State, Brazil

*Corresponding author: José Cláudio Simão, Department of Tropical Diseases, Botucatu Medical School, São Paulo State University (UNESP), City of Botucatu, São Paulo State, Distrito de Rubião Junior, S/N CEP/ZIP 18618-970, Brazil, Tel: +5514-3882-1284, Fax: +55-14-3811-1515

\begin{abstract}
Introduction: The expansion of Visceral Leishmaniasis in areas of recent emergency in the last two decades in Brazil can be understood by spatial analysis.

Methodology: Study of the spatial distribution of general VL and VL-HIV coinfection in the city of Bauru - SP, Brazil between 2003 to 2016 . The cases were georeferenced and attributed to the Census sectors using demographic, socioeconomic and urban infrastructure predictors. The incidence in these sectors was analyzed in univariate and multivariate one-step Poisson regression models.

Results: The cumulative incidence rates of LV and LVHIV (per 100,000 inhab.) In this period were 131.1 and 19.7, respectively. In the univariate analysis, the spatial distribution of VL and VL-HIV co-infection was negatively associated with per capita income, population density, paving and proportion of streets in sidewalks and rain drainage. In multivariable models, the incidence of VL was negatively associated with per capita income (Incident Rate Ratio [IRR], 0.89; 95\% confidence interval [Cl], 0.860.92 ) and population density (IRR, $94 ; 95 \% \mathrm{Cl}, 0.90-0.97)$, while co-infection was negatively associated with per capita income (IRR, $0.80 ; 95 \% \mathrm{Cl}, 0.71-0.91)$ and proportion of streets with rain drainage (TIR, 0.87; 95\% Cl, 0.78-0.98).
\end{abstract}

Conclusion: Demographic, socioeconomic and infrastructure deficits can influence the emergence patterns of $\mathrm{VL}$ in urban areas in developing countries.

\section{Keywords}

Visceral leishmaniasis, Leishmania-HIV coinfection, Spatial epidemiology

\section{Introduction}

Visceral Leishmaniasis (VL) is a relevant cause of morbidity and mortality in many developing countries [1]. In the past three decades, VL in Brazil changed from rural endemics of Northeastern States into an emergent disease of great urban centers [2]. The area affected spread southwards affecting São Paulo, the most populous state in the country. In this setting, the epidemics of VL and AIDS intertwined [3].

In urban areas of recent emergence, the spatial distribution of VL cases is not homogeneous [4]. Previous studies suggest that socioeconomic and environmental factors may shape de spatial distribution $V L$ incidence [5]. Therefore, the study of those factors is likely to provide clues to determinants of the emergence of VL, ultimately pointing to areas/populations at risk and helping in directing preventive measures [6].

\section{Methodology}

We studied the spatial distribution of overall VL

Citation: Simão JC, Victória C, Fortaleza CMCB (2021) Factors Affecting the Spatial Distribution of Visceral Leishmaniasis in an Urban Area of Recent Emergence in Inner Brazil. Int J Trop Dis 4:051. doi. org/10.23937/2643-461X/1710051

Accepted: August 19, 2021; Published: August 21, 2021

Copyright: (C) 2021 Simão JC, et al. This is an open-access article distributed under the terms of the Creative Commons Attribution License, which permits unrestricted use, distribution, and reproduction in any medium, provided the original author and source are credited. 
and VL-HIV coinfection in the city of Bauru $(340.000$ inhabitants), inner São Paulo State, Brazil. That city is located at $22^{\circ} 18^{\prime} 55^{\prime \prime} \mathrm{S}, 49^{\circ} 3^{\prime} 41^{\prime \prime} \mathrm{W}$, and at an altitude of 543 meters. The first notifications of VL in Bauru date from 2003. The cumulative incidence rates of VL and VLHIV (per 100,000 inhabitants) in the period 2003-2016 were 131.1 and 19.7, respectively.

The addresses of subjects were georeferenced in QGIS 2.18 (QGIS Development Team [2016]. QGIS Geographic Information System. Open Source Geospatial Foundation Project. http://qgis.osgeo.org"), using UFT-8 codifications and MMQGIS geocodification algorithm. After georeferencing, cases were assigned to census sectors of the city of Bauru, Brazil, according to Brazilian Institute of Geography and Statistics (IBGE). Kernel density maps were generated in ArcGis 10.1 (ESRI, Redlands, CA) using the following algorithms: "integrate", "collect events" and "hotspot analysis".

Census sectors were the units for analysis of predictors of VL and VL-HIV incidence. Variables included in the analysis were collected in the 2010 Brazilian Census Data (IBGE) and included and per capita income and population density. Other data collected from the same source included percentage of houses in places with sidewalks, paving of streets, drains for rainfall, trees, sewage and garbage in the open. Data were analyzed in Stata 14 (College Station, TX), using univariate and multivariable (single-step) models of Zero-inflated Poisson Regression.

\section{Results}

Figure 1 presents spatial distribution of cases, in crude incidence per census sectors and Kernel densities. Predictors of geographic incidence are presented in Table 1. In multivariable models, overall VL incidence was negatively associated with population density and per capita income, while there was negative association of the incidence of VL-HIV coinfection with per capita income and presence of drains for rainfall.

\section{Discussion}

Our results provide clues to the routes of urbanization of $V L$ and intersection of VL and AIDS epidemics. In univariable analysis, several aspects linked to poverty (e.g., absence of sidewalks and paving of streets, presence of garbage in the open) were associated with the outcomes. Those environmental factors may be proxies for both the presence of vectors (Lutzomyia longipalpis) breeding sites (usually sites with decaying organic matter) and of reservoirs (domiciled or stray dogs) $[7,8]$.
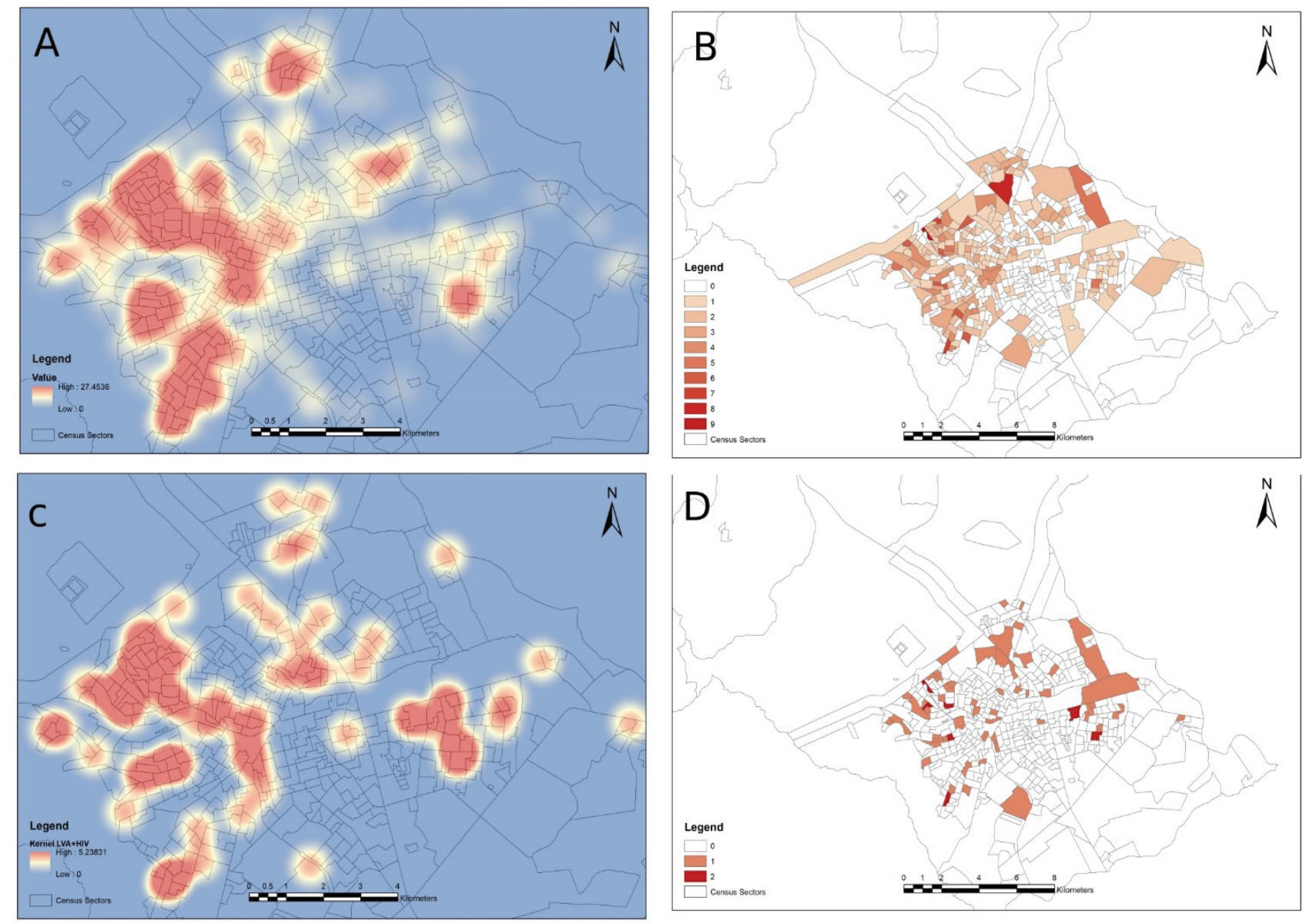

Figure 1: Spatial distribution of Visceral Leishmaniasis (VL) and VL-HIV coinfection in the city of Bauru, inner Brazil (A,B) Kernel density map and absolute incidence of overall VL; $(C, D)$ Kernel density map and absolute incidence of VL-HIV coinfection. 
Table 1: Factors associated with the incidence of Visceral Leishmaniasis (VL) and VL-HIV coinfection among census sectors in the city of Bauru, inner Brazil.

\begin{tabular}{|c|c|c|c|c|}
\hline \multirow{2}{*}{ Factors } & \multicolumn{2}{|l|}{ Univariate } & \multicolumn{2}{|l|}{$0.89(0.86-0.92)$} \\
\hline & IRR $(95 \% \mathrm{Cl})$ & $P$ & IRR (95\%Cl) & $P$ \\
\hline \multicolumn{5}{|l|}{ Overall VL } \\
\hline Population density & $0.95(0.92-0.99)$ & 0.006 & $0.94(0.90-0.97)$ & $<0.001$ \\
\hline Per capita income $(\mathrm{BRL} \times 100)$ & $0.90(0.87-0.92)$ & $<0.001$ & $0.89(0.86-0.92)$ & $<0.001$ \\
\hline Paving of streets $(\times 10 \%)$ & $0.93(0.90-0.96)$ & $<0.001$ & $1.01(0.92-1.10)$ & 0.87 \\
\hline Sidewalks (× 10\%) & $0.92(0.90-0.95)$ & $<0.001$ & $0.99(0.91-1.09)$ & 0.91 \\
\hline Drains for rainfall $(\times 10 \%)$ & $0.94(0.90-0.98)$ & 0.002 & $0.96(0.92-1.00)$ & 0.08 \\
\hline Trees $(\times 10 \%)$ & $1.03(0.92-1.10)$ & 0.57 & $0.92(0.80-1.05)$ & 0.21 \\
\hline Sewage in the open $(\times 10 \%)$ & $1.08(0.93-1.27)$ & 0.33 & $1.09(0.91-1.31)$ & 0.36 \\
\hline Garbage in the open $(\times 10 \%)$ & $1.06(1.02-1.12)$ & 0.004 & $1.00(0.95-1.06)$ & 0.96 \\
\hline \multicolumn{5}{|l|}{ VL-HIV coinfection } \\
\hline Population density & $0.97(0.90-1.05)$ & 0.48 & $0.94(0.86-1.03)$ & 0.18 \\
\hline Per capita income $(\mathrm{BRL} \times 100)$ & $0.85(0.78-0.93)$ & $<0.001$ & $0.80(0.71-0.91)$ & $<0.001$ \\
\hline Paving of streets $(\times 10 \%)$ & $0.92(0.85-0.98)$ & 0.02 & $0.95(0.90-1.19)$ & 0.67 \\
\hline Sidewalks $(\times 10 \%)$ & $0.92(0.86-0.99)$ & 0.03 & $1.09(0.87-1.37)$ & 0.44 \\
\hline Drains for rainfall $(\times 10 \%)$ & $0.86(0.77-0.95)$ & 0.004 & $0.87(0.78-0.98)$ & 0.02 \\
\hline Trees $(\times 10 \%)$ & $1.04(0.81-1.32)$ & 0.76 & $0.94(0.73-1.19)$ & 0.60 \\
\hline Sewage in the open $(\times 10 \%)$ & $11.08(0.66-1.78)$ & 0.76 & $1.27(0.76-2.13)$ & 0.36 \\
\hline Garbage in the open $(\times 10 \%)$ & $0.99(0.87-1.13)$ & 0.89 & $0.86(0.74-1.01)$ & 0.07 \\
\hline
\end{tabular}

VL: Visceral Leishmaniasis; HIV: Human Immunodeficiency Virus; BRL: Brazilian Currency (real, approx imately US\$ 0.25); IRR: Incidence Rate Ratio; $\mathrm{Cl}$ : Confidence Interval

Similarly to our results, proxy indicators of poverty such as (illiteracy and income) have been described both in areas of early [9] and recent emergence [10]. Urban VL has been associated with living in the periphery of cities, which are sites where favelas and poor neighborhoods are located. Not surprisingly, those are areas of greater prevalence of HIV infection [10].

\section{Conclusion}

Taken together, all those findings reinforce the social and economic determination in the distribution of $V L$ and VL-coinfection. Since a recent systematic review failed to identify effective measures to prevent $V L$ in Latin America [11,12], interventions aimed at improving income and housing conditions may be pathways for controlling this disease.

\section{References}

1. Hailu T, Yimer M, Mulu W, Abera B (2016) Challenges in visceral leishmaniasis control and elimination in the developing countries: A review. J Vector Borne Dis 53: 193-198.

2. Arias JR, Monteiro PS, Zicker F (1996) The reemergence of visceral leishmaniasis in Brazil. Emerg Infect Dis 2: 145146.

3. Leite de Sousa-Gomes M, Romero GAS, Werneck GL (2017) Visceral leishmaniasis and HIVIAIDS in Brazil: Are we aware enough? PLoS Negl Trop Dis 11: e0005772.

4. Cardim MF, Vieira CP, Chiaravalloti-Neto F (2015) Spatial and spatiotemporal occurrence of human visceral leishmaniasis in Adamantina, State of São Paulo, Brazil. Rev Soc Bras Med Trop 48: 716-723.
5. Silva TAMD, Coura-Vital W, Barbosa DS, Oiko CSF, Morais MHF, et al. (2017) Spatial and temporal trends of visceral leishmaniasis by mesoregion in a southeastern state of Brazil, 2002-2013. PLoS Negl Trop Dis 11: e0005950.

6. Ursine RL, Dias JVL, Morais HA, Pires HHR (2016) Human and canine visceral leishmaniasis in an emerging focus in Araçuaí, Minas Gerais: Spatial distribution and socioenvironmental factors. Mem Inst Oswaldo Cruz 111: 505511.

7. Casanova C, Andrighetti MTM, Sampaio SMP, Marcoris MLG, Colla-Jacques FE, et al. (2013) Larval breeding sites of Lutzomyia longipalpis (Diptera: Psychodidae) in visceral leishmaniasis endemic urban areas in Southeastern Brazil. PLoS Negl Trop Dis 7: e2443.

8. Teixeira-Neto RG, da Silva ES, Nascimento RA, Belo VS, de Oliveira CD, et al. (2014) Canine visceral leishmaniasis in an urban setting of Southeastern Brazil: An ecological study involving spatial analysis. Parasit Vectors 7: 485.

9. de Almeida AS, Medronho R de A, Werneck GL (2011) Identification of risk areas for visceral leishmaniasis in Teresina, Piaui State, Brazil. Am J Trop Med Hyg 84: 681-687.

10. de Araújo VEM, Pinheiro LC, Almeida MC, de Menezes FC, Morais MHF, et al. (2013) Relative risk of visceral leishmaniasis in Brazil: A spatial analysis in urban area. PLoS Negl Trop Dis 7: e2540.

11. Alves ATJ, Nobre FF, Waller LA (2016) Exploring spatial patterns in the associations between local AIDS incidence and socioeconomic and demographic variables in the state of Rio de Janeiro, Brazil. Spat Spatiotemporal Epidemiol 17: 85-93.

12. Romero GAS, Boelaert M (2010) Control of visceral leishmaniasis in Latin America-a systematic review. PLoS Negl Trop Dis 4: e584. 